\title{
O processo de edição filológica de documentos utilizando o software eDictor
}

\author{
Daiana da Silva Teixeira \\ Universidade de São Paulo, Faculdade de Filosofia, Letras e Ciências Humanas, Departamento Letras \\ Clássicas e Vernáculas, São Paulo, SP, Brasil \\ daiana.teixeira@usp.br \\ Mayara Feliciano Palma \\ Universidade de São Paulo, Faculdade de Filosofia, Letras e Ciências Humanas, Departamento Letras \\ Clássicas e Vernáculas, São Paulo, SP, Brasil \\ Brasil \\ mayara.palma@usp.br
}

Patrícia Brasil

Universidade de São Paulo, Faculdade de Filosofia, Letras e Ciências Humanas, Departamento Letras Clássicas e Vernáculas, São Paulo, SP, Brasil patricia.brasil.silva@usp.br

Sofia Tonoli Maniezo Zani

Universidade de São Paulo, Faculdade de Filosofia, Letras e Ciências Humanas, Departamento Letras Clássicas e Vernáculas, São Paulo, SP, Brasil sofia.zani@usp.br

DOI: https://doi.org/10.26512/rici.v13.n1.2020.29614

Recebido/Recibido/Received: 2019-12-30

Aceitado/Aceptado/Accepted: 2020-02-14

Resumo: Partindo da discussão sobre as chamadas Humanidades Digitais, queremos, neste trabalho, mostrar como o Projeto Mulheres na América Portuguesa (MAP) se insere nesse campo ao trabalhar com a difusão, no meio digital, de documentos escritos por mulheres ou que se referem a mulheres entre 1500-1822. Ao buscarmos esses documentos (de diversas tipologias, como cartas, processos inquisitoriais, requerimentos etc.) em arquivos com catálogos digitais (como o Arquivo Público do Estado de São Paulo), bem como em arquivos com amplo acervo digitalizado (como o Arquivo Nacional da Torre do Tombo de Lisboa), percebemos a inexistência de uma chave de busca que os selecionasse de acordo com a presença da mulher como autora ou referida. Assim, valendo-se dos documentos já disponíveis nesses e em outros acervos que disponibilizam reproduções digitais dos documentos, o MAP propõe a construção de um catálogo próprio, o qual vem sendo construído digitalmente em linguagem XML. Portanto, estamos formando um corpus, reunindo essas mulheres autoras ou referidas. Para que possamos construir um catálogo com essa temática, estamos preparando transcrições e edições filológicas desses documentos. Considerando que o intuito é democratizar o acesso ao disponibilizar online tais escritos, usamos o software eDictor, que consiste em um editor de textos destinado ao trabalho filológico e que permite a realização de análises linguísticas. Além disso, é possível elaborar edições modernizadas de manuscritos, sem que se percam as informações filológicas relevantes do texto original. $O$ desenvolvimento e a utilização de tecnologias digitais como o eDictor, pelo Projeto MAP, se inserem na tendência de aproximação das humanidades com as ciências computacionais. A partir dos resultados que temos obtido, podemos afirmar que o uso do eDictor favorece a qualidade da edição filológica dos manuscritos e possibilita o acesso de pesquisadores de diversas áreas e de um público mais amplo a esses documentos. Essas vantagens nos dão a perspectiva de intensificação do uso 
e aprimoramento do software, de modo a ampliar as possibilidades de construção de corpora de textos. Dessa forma, no MAP, os recursos digitais são considerados tanto como ferramentas aplicadas quanto como produtos, ou seja, recursos gerados pelo projeto.

Palavras-chave: mulheres. Brasil. Filologia. edições eletrônicas. humanidades digitais.

\section{The philological documents editing process using the Edictor software}

Abstract: Starting from the discussion about the so-called Digital Humanities, we want, in this paper, to show how the Women in Portuguese America Project (MAP in Portuguese) fits into this field by working with the digital diffusion of documents written by women or referring to women between 1500-1822. When we search for these documents (of various types, such as letters, inquisitorial processes, requirements, etc.) in archives with digital catalogs (such as the Public Archive of the State of São Paulo), as well as archives with a large digitized collection (such as the National Archives of Torre do Tombo de Lisboa), we noticed the lack of a search key that would select them according to the presence of the woman as author or referee. Thus, drawing on the documents already available in these and other collections providing digital reproductions of the documents, MAP proposes the construction of its own catalog, which has been digitally built in XML language. Therefore, we are forming a corpus, bringing together these women authors or referred. So that we can build a catalog with this theme, we are preparing transcriptions and philological editions of these documents. Considering that the purpose is to democratize access by making such writings available online, we use the eDictor software, which consists of a text editor for philological work and which allows linguistic analysis. In addition, it is possible to elaborate modernized editions of manuscripts without losing the relevant philological information of the original text. The development and use of digital technologies such as eDictor, by the MAP Project, are part of the tendency of the humanities to approach the computer sciences. From the results we have obtained, we can say that the use of eDictor favors the quality of the philological editing of manuscripts and allows researchers from various areas and a wider public to access these documents. These advantages give us the perspective of intensifying the use and improvement of the software, in order to expand the possibilities of text corpora construction. Thus, in MAP, digital resources are considered as both applied tools and products, i.e. resources generated by the project.

Keywords: women's history. Brazil. Philology. electronics editions. digital humanities.

\section{El proceso de edición filológica de documentos usando el software eDictor}

Resumen: A partir de la discusión sobre las llamadas Humanidades Digitales queremos, en este trabajo, mostrar cómo el Proyecto Mujeres en América Portuguesa (MAP) encaja en este campo pues trabaja con la difusión, en el medio digital, de documentos escritos por mujeres o que se refieren a mujeres entre 1500-1822. Al buscar estos documentos (de diferentes tipos, como cartas, procesos inquisitoriales, requisitos, etc.) en archivos con catálogos digitales (como el Archivo Público del Estado de São Paulo), así como en archivos con una gran colección digitalizada (como el Archivo Nacional de Torre do Tombo de Lisboa), notamos la falta de una clave de búsqueda que los seleccionara de acuerdo con la presencia de la mujer como autora o referida. Por lo tanto, utilizando los documentos ya disponibles en estas y otras colecciones que proporcionan reproducciones digitales de los documentos, MAP propone la construcción de su propio catálogo, que ha sido construido digitalmente en lenguaje XML. Entonces, estamos formando un corpus, reuniendo a estas mujeres autoras o referidas. Para poder construir un catálogo con este tema, estamos preparando transcripciones y ediciones filológicas de estos documentos. Teniendo en cuenta que el objetivo es democratizar el acceso de modo que tales escritos estén disponibles en línea, utilizamos el software eDictor, el cual consiste en un editor de texto para el trabajo filológico y permite el análisis lingüístico. Además, es posible preparar ediciones modernizadas de manuscritos, sin perder la información filológica relevante del texto original. El desarrollo y uso de tecnologías digitales como eDictor, por el Proyecto MAP, son parte de la tendencia de acercar las humanidades a las ciencias de la computación. De los resultados que hemos obtenido, podemos decir que el uso de eDictor favorece la calidad de la edición filológica de los manuscritos y permite el acceso de investigadores de diferentes áreas y una audiencia más amplia a estos documentos. Estas ventajas nos han dado la perspectiva de intensificar el uso y la mejora del software, a fin de ampliar las posibilidades de crear corpus de texto. Por lo tanto, en M.A.P., los recursos digitales se consideran tanto herramientas aplicadas como productos, es decir, recursos generados por el proyecto. Palabras clave: mujeres. Brasil. Filología. ediciones electrónicas. humanidades digitales. 


\section{Projeto Mulheres na América Portuguesa (MAP)}

O projeto Mulheres na América Portuguesa (MAP) se insere no Grupo de pesquisa em Humanidades Digitais, que faz parte do Núcleo de Apoio à Pesquisa em Etimologia e História da Língua Portuguesa da Universidade de São Paulo (USP). Nesse cenário, o MAP tem como objetivo realizar a edição e catalogação de documentos manuscritos por mulheres ou sobre mulheres no Brasil e no espaço atlântico português, especificamente, no período de 1500 a 1822 (PAIXÃO DE SOUSA E MONTE, 2018, 2019), época em que o país era colônia de Portugal. Considerando que "no teatro da memória, as mulheres são sombras tênues"(PERROT, 1989 apud PAIXÃO DE SOUSA E MONTE, 2018, 2019), o desenvolvimento desse projeto é relevante também para o resgate da memória de mulheres esquecidas pela história, principalmente, daquelas que não eram figuras ilustres.

Para isso, lançamos mão da Filologia, que geralmente é definida como a ciência que se preocupa com o estudo científico de textos escritos, sua transmissão, a fim de estabelecer, editar e interpretar esses textos. Além disso, por meio da Filologia - que não deve ser vista como uma mera disciplina acessória para outras ciências - podemos descobrir a origem temporal e espacial de documentos, ou seja, em que época e onde foi produzido e também podemos levantar hipóteses sobre o processo de escrita, como, por exemplo, se um texto foi escrito por uma ou mais pessoas (figura 1.

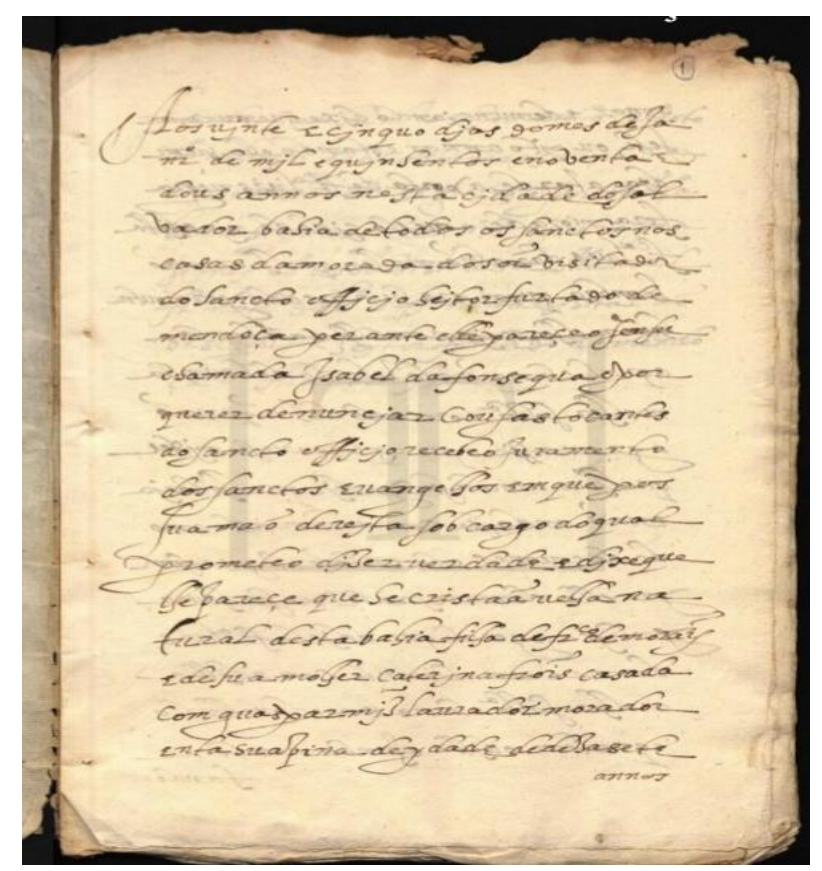

Figura 1 - Exemplo de documento estudado pela Filologia. Arquivo Nacional Torre do Tombo (2011) 
Assim, tendo em mente nosso propósito no MAP, nos aproximamos da ideia de que "[...] o filólogo administra um patrimônio [...] logo, o filólogo é um curador textual." (FERREIRA, 2016, p. 231). Nesse sentido, entendemos que o texto é análogo a uma obra artística que se encontra em um museu, a qual deve ser preservada e que às vezes precisa passar por processos de restauração. Também há quem tente realizar interpretações e levantar hipóteses sobre determinada obra, como as características de sua autora ou autor, ou as técnicas que foram empregadas para a composição da obra - assim também é o texto.

Para desenvolver esse trabalho, a divisão do trabalho no MAP é organizada em grupos, os quais chamamos de "Frentes", desse modo, cada Frente é responsável por realizar determinadas tarefas. A seguir, as apresentamos e esclarecemos que função cada uma exerce dentro do Projeto.

A de Frente de Filologia é responsável pela pesquisa de documentos em acervos físicos e digitais, bem como pela edição dos documentos relevantes para o Projeto. A Frente Computacional têm como função o uso de recursos digitais para auxiliar o trabalho das pesquisadoras, assim, se relaciona diretamente com as Humanidades Digitais. A Frente Linguística se preocupa com as análises linguísticas após a finalização das edições filológicas, tais análises também contam com o uso de recursos digitais.

A Frente de Extroversão realiza a divulgação científica nas redes sociais e no blog do MAP, o que permite estabelecer a importante relação entre ciência e sociedade, mostrando as atividades realizadas pela equipe de pesquisadoras, bem como outros conteúdos produzidos por elas. Por último, a Frente de Iconografia pesquisa por imagens representativas da temática do Projeto MAP e arquivo das mesmas para que sejam usadas nas redes sociais, painéis ou outros suportes.

Na sequência, explicamos como integramos a Filologia e computação, enfocando as seguintes etapas de nossa metodologia: a busca por documentos e a criação do catálogo MAP, a aplicação a linguagem XML e o uso software eDictor no Projeto. Depois disso, destacamos algumas vantagens dessa metodologia e seus resultados, por último, tecemos algumas considerações finais sobre todo esse processo.

\section{A busca por documentos e a criação do catálogo MAP}

A pesquisa em nosso projeto começa nos arquivos, sejam eles físicos ou digitais. Até o presente momento, grande parte dos documentos de nosso interesse - que apresentam tipologia muito diversa e são, portanto, um conjunto documental de difícil reunião - são acessados por meio de repositórios digitais, como o Arquivo Nacional da Torre do Tombo (ANTT), o Arquivo Público Mineiro (APM) e o Projeto Post Scriptum, da Universidade de Lisboa. 
Desses, apenas o segundo apresenta um filtro que nos permite encontrar textos baseados em nosso principal critério: o gênero - isto é, textos que sejam escritos por ou sobre mulheres.

Diante desse problema, e para que a nossa busca em arquivos se tornasse mais minuciosa, foi necessário criar uma metodologia de busca que atendesse os interesses do projeto e das pesquisadoras. Com a leitura de uma bibliografia contemporânea e relevante sobre a história das mulheres na América Portuguesa encontramos elementos que nos permitiram criar chaves de pesquisa para os sistemas de busca dos arquivos. O recurso mais produtivo dessa metodologia, até agora, foi o uso de termos biográficos variáveis em gênero gramatical, mas buscamos também pelo assunto do documento - o que requer uma separação manual daqueles documentos que de fato são protagonizados por uma mulher - por profissão e pelo estatuto social. Os termos usados - cristã-nova, cristã-velha, escrava, preta forra, heresia, bigamia, traição, tabuleiro - foram registrados em um glossário, baseado na recorrência deles em nossos documentos, onde as demais pesquisadores poderiam consultar quais entradas já existiam ou adicionar novas entradas.

A pesquisa com os termos-chave possibilitou a reunião de documentos inéditos e com grande potencial para pesquisas futuras. Com isso, o Projeto Mulheres na América Portuguesa tem como principal objetivo a reunião virtual de documentos autorais e sobre mulheres do período colonial brasileiro, em um catálogo eletrônico online, já que um problema até mesmo anterior ao dos filtros na busca em arquivos, é o da dificuldade em encontrar fontes primárias de e sobre mulheres, ainda mais de forma reunida.

O Catálogo $\mathrm{MAP}^{1}$ se organiza com dois tipos básicos de entradas ou grupos de documentos: o de mulheres autoras de documentos primários, que é o grupo mais importante, mas também o mais escasso; e o maior grupo, o de mulheres nomeadas em documentos primários por meio de discurso relatado em processos, denúncias, confissões ou autos de devassa. Cada uma das entradas contém informações biográficas sobre a mulher, conforme descritas no documento ou em bibliografia relevante, e sobre o próprio documento; quando disponíveis. No catálogo aparecem também as reproduções digitais dos documentos e um trecho de sua transcrição.

\footnotetext{
${ }^{1}$ Disponivel em http://map.prp.usp.br/MAP_Recursos.html
} 


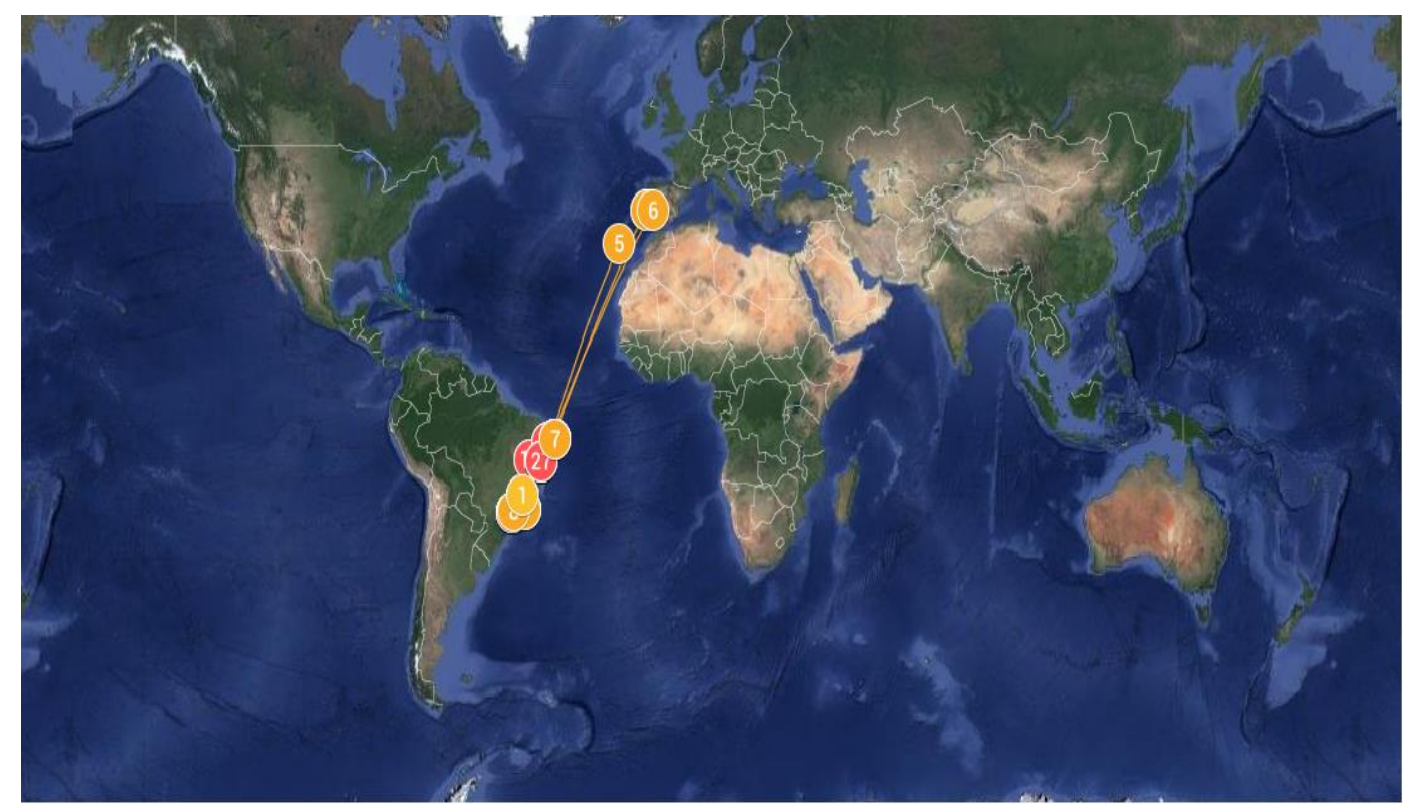

Figura 2: Panorama do Catálogo no Google Maps Paixão de Sousa e Monte (2019)

A visualização do Catálogo pode ser feita na forma de dados georreferenciados, pelo Google Maps, como mostra a imagem (Figura 2). Nela, números são gerados em certos pontos do mapa, identificando os locais em que os documentos foram produzidos. No caso das cartas, é possível ver a trajetória feita pela correspondência, o que evidencia a relação entre o que chamamos de América Portuguesa, isto é, Brasil e Portugal. Além disso, a visualização pode ser feita também por fichas individuais, sendo cada uma delas correspondente ao nome de uma mulher. $\mathrm{O}$ cuidado com a inserção de todas essas informações se deve ao trabalho para além do Catálogo, como a investigação no campo da filologia e da linguística histórica, realizada dentro do próprio MAP, bem como para servir a outras pesquisas futuras.

\section{A aplicação da linguagem XML}

Tivemos grande dificuldade para inserir todas as informações dos documentos em linguagem $X M L$, pois inserir os documentos diretamente no XML do site se configura como programação. Quando éramos um pequeno grupo de pesquisadoras, aprendemos alguns conceitos básicos sobre o assunto. Contudo, com o aumento do número de pesquisadoras, se tornou cada vez mais difícil ensinar todas a programar. Além disso, outros obstáculos eram: apenas uma pesquisadora por vez podia lidar com o XML a fim de evitar conflitos entre as informações e havia grande margem de erro, já que a interface dessa linguagem não é muito intuitiva (ver figura 3). 


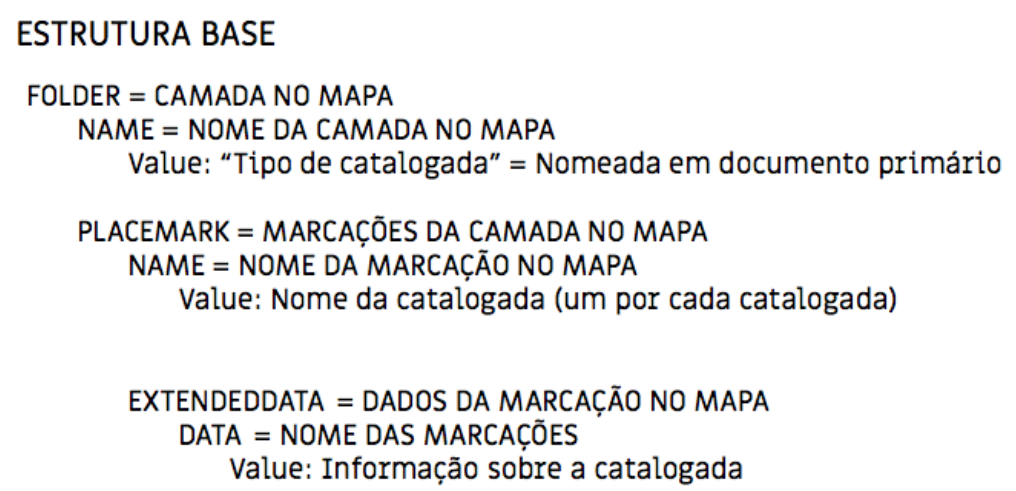

Figura 3: Interface em linguagem XML MAP (2019)

Para tanto, a pesquisadora Priscila Tuy, em colaboração com um pesquisador da área de computação, sob orientação da Professora Orientadora Maria Clara Paixão de Souza, temos a criação de uma interface para facilitar e agilizar o preenchimento do catálogo. Com um protótipo feito, esperamos otimizar o preenchimento do catálogo através da interface. Cada pesquisadora terá um login e senha para fazer a catalogação dos documentos. A estrutura da interface será flexível e online,o que significa que podemos mudar, acrescentar ou reduzir as chaves de catalogação, caso haja necessidade; também, desde que haja internet, as pesquisadoras poderão fazer o login e catalogar de onde elas estiverem. A interface funciona, assim, como um intermediário entre a pesquisadora e o catálogo, e uma das vantagens mais importantes é o fato de que mais de uma pesquisadora pode editar o catálogo ao mesmo tempo, uma vez que o número da catalogada será gerado automaticamente, ao invés de manualmente. Isso evitará o erro de dois documentos terem o mesmo número de catalogação. 


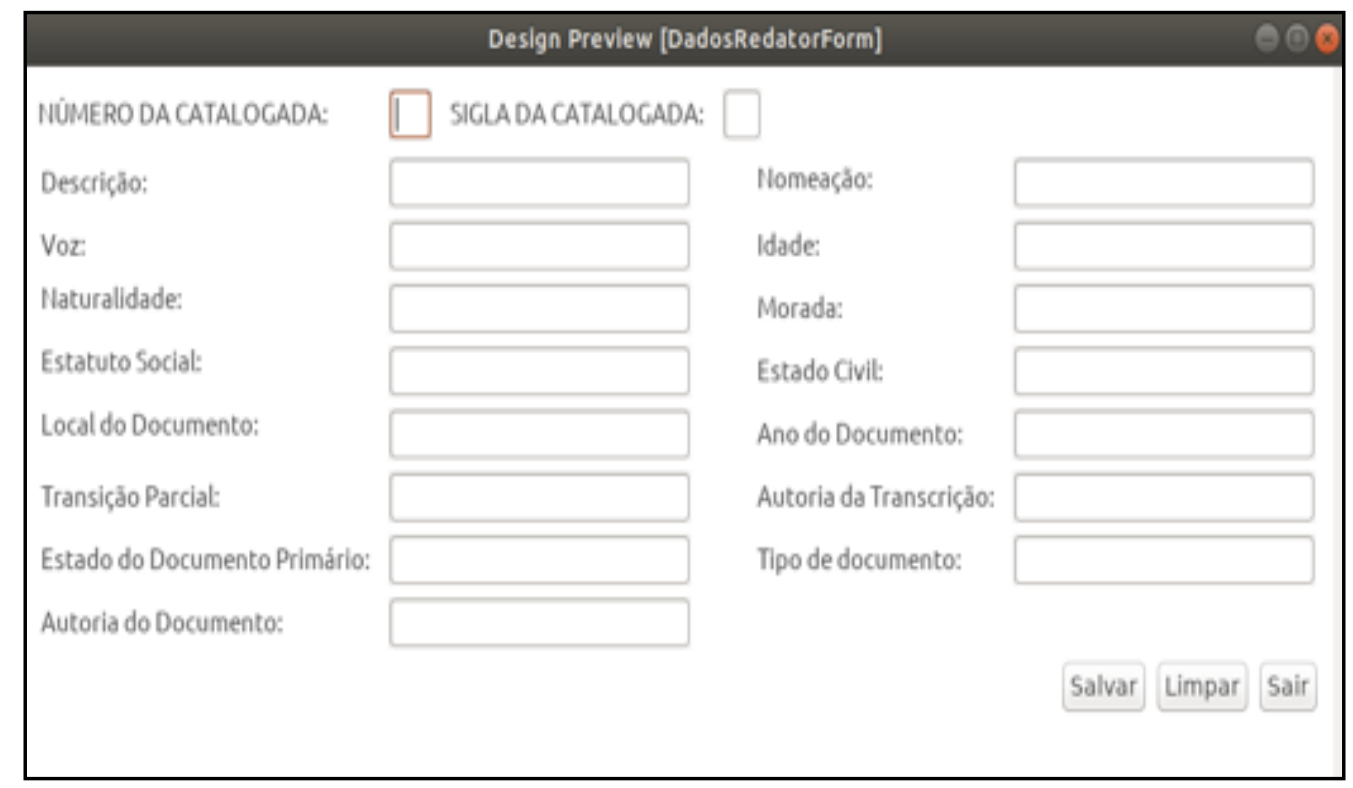

Figura 4: Protótipo de interface para a catalogação de documentos MAP (2019)

\section{0 uso do software eDictor no MAP}

No contexto das Humanidades Digitais, as tecnologias são adaptadas aos campos de pesquisa humanística. No entanto, não se trata apenas de construir uma tecnologia inexistente no mercado, mas de conceber uma ferramenta computacional adaptada às necessidades específicas desses campos. No Projeto Mulheres na América Portuguesa (MAP), cujo intuito é disponibilizar online os documentos escritos por mulheres ou que se referem a mulheres entre 1500-1822, o desafio consiste na adaptação das edições textuais a edições digitais; de modo que se mantenha a qualidade da edição filológica dos manuscritos e possibilite o acesso de pesquisadores de diversas áreas e de um público mais amplo a esses documentos. Considerando essa necessidade, utilizamos o software eDictor, que consiste em um editor de textos destinado ao trabalho filológico e que permite a realização de análises linguísticas automáticas (PAIXÃO DE SOUSA, KEPLER \& FARIA, 2013).

As humanidades e a tecnologia computacional se relacionam de forma a contribuir, mutuamente, para a evolução de ambos os campos. Com o uso de bancos de dados adaptados para o conteúdo humanístico, todo o conjunto de objetos culturais que são intrínsecos a um campo de estudo específico constitui um campo em expansão, o qual serve à análise comparativa e global de toda a matéria cultural. Nessa perspectiva de colaboratividade, a democratização do acesso aos escritos antigos contribui, em certa medida, para que a história seja estudada e interpretada por vários campos humanísticos a partir do contato com a memória. 
Assumimos, assim, que as Humanidades Digitais constituem uma forma de interdisciplinaridade centrada na aplicação de ideias, métodos e conhecimentos de cada campo das Humanidades. Nesse contexto, a interdisciplinaridade se dá por meio de um trabalho colaborativo e compartilhado, com resultados abertos à contemplação da comunidade acadêmica e do público amplo. Isso nos leva a admitir que o uso de soluções tecnológicas baseadas em softwares livres se coaduna com o objetivo de facilitar as colaborações entre as disciplinas e alcançar resultados e avanços globalmente. Ao mesmo tempo, possibilita ganhos e trocas de conhecimento que, além de otimizar a gerência dos recursos financeiros e do tempo, podem propiciar questões e resultados inovadores para o trabalho filológico com escritos antigos.

Nesse sentido, uma das possibilidades decorrentes da aplicação das tecnologias digitais ao trabalho filológico é a análise linguística sob o olhar diacrônico. Paixão de Sousa, Kepler e Faria (2010) observam que as edições eletrônicas satisfazem questões essenciais ao estudo das mudanças linguísticas no decorrer do tempo. No entanto, para a validade desses estudos, é fundamental a garantia de fidelidade do texto transcrito aos escritos originais. Para isso, ao se inserir no campo Humanidades Digitais, o Projeto MAP faz uso do software eDictor; um editor de textos especialmente voltado ao trabalho filológico e à análise linguística automática, que permite conservar a edição original do texto.

Por meio do eDictor, os textos podem ser adaptados à ortografia atual e receber diferentes camadas de anotação linguística e filológica, pelo sistema de edição eletrônica. Assim, a partir de um arquivo XML é possível gerar diferentes versões de apresentação do texto (edição diplomática, edição semidiplomática acompanhas pelo fac-símile, uma versão de texto original em .txt e outras). E, atendendo à condição do estudo linguístico, de fidelidade do texto, o escrito original é conservado nesse tipo de edição. O que acontece é a adição de camadas sobre esse texto; de modo que a sua forma original, ou conservadora, sempre será mantida junto com as demais versões de edição. 


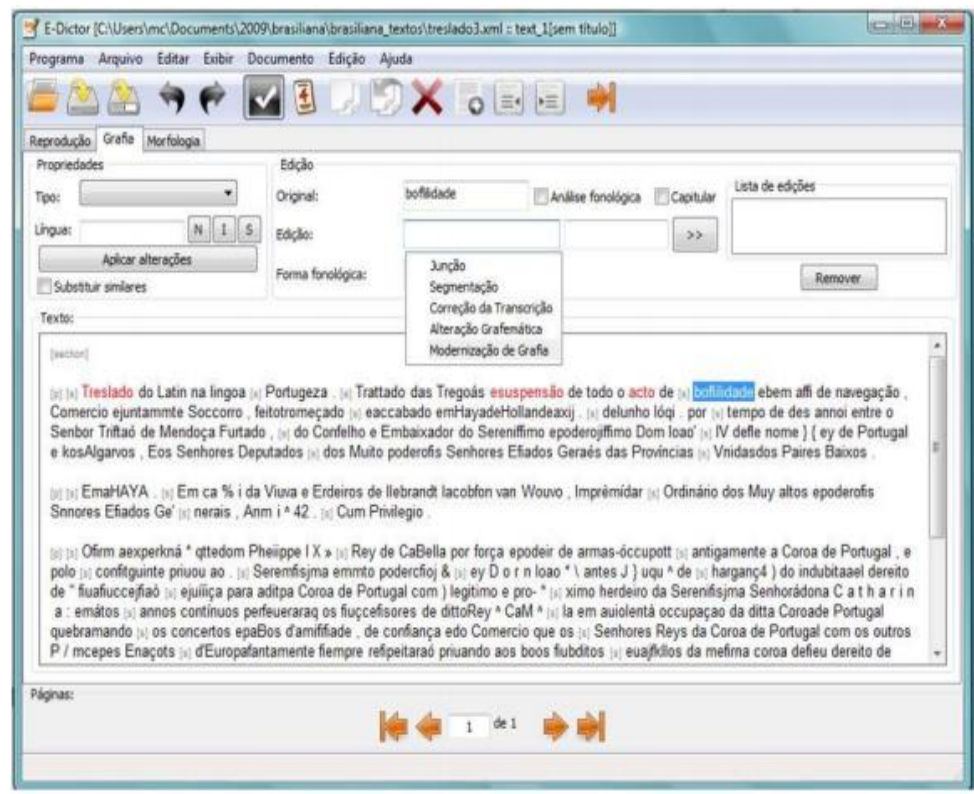

Figura 5: Interface Gráfica do eDictor Paixão de Sousa; Kepler; Faria, 2010

Segundo Paixão de Sousa et. al. (2010), no desenvolvimento dessa ferramenta, pretendia-se absorver as vantagens do sistema de anotação em XML para as edições filológicas, mas que possibilitasse uma interface amigável e confiável, além de integração entre o sistema de edição e o sistema de correção da anotação morfológica. No trabalho de edição em meio digital, as pesquisadoras carregam o programa com as preferências que desejarem e com as etiquetas necessárias para a edição de seus textos.

\section{Resultados}

A partir dos resultados que temos obtido, podemos afirmar que o uso do eDictor favorece a qualidade da edição filológica dos manuscritos e possibilita o acesso de pesquisadores de diversas áreas e de um público mais amplo a esses documentos. Essas vantagens nos dão a perspectiva de intensificação do uso e aprimoramento do software, de modo a ampliar as possibilidades de construção de corpora de textos, devendo torná-los acessíveis por meio de programas de busca. Além disso, ao permitir a edição digital de textos antigos transcritos, o software possibilita a exibição desse texto em camadas com o passar do cursor; sendo útil a esses escritos cujas grafias são de difícil leitura, pois, além de facilitá-la, contribui com a edição colaborativa no formato digital.

Essa interação do próprio leitor com o material, por meio do eDictor, significa uma mudança de paradigma no estudo das humanidades: o leitor decide o que quer ver e interage com a própria ferramenta, deixando de ser apenas receptor do conhecimento. Constrói-se assim um sistema de troca de dados em que todas as informações podem ser interconectadas, 
com o objetivo de criar um grande banco de textos, que constituem fonte e resultado de pesquisas de diferentes disciplinas, permitindo uma perspectiva mais abrangente e global.

Os diferentes tipos de materiais que são catalogados oferecem possibilidades de análise a diversas áreas do conhecimento. No caso dos manuscritos, por exemplo, os resultados podem ser analisados sob diferentes perspectivas ao aglutinar problemas comuns a disciplinas diferentes, adicionando uma camada digital com uma finalidade específica. Temos, portanto, a interdisciplinaridade e a inovação como elementos importantes nessa rede colaborativa digital.

\section{Considerações finais}

O Projeto Mulheres na América Portuguesa (MAP) se insere no campo Humanidades Digitais ao trabalhar com a difusão, no meio digital, de documentos escritos por mulheres ou que se referem a mulheres. Dessa forma, no MAP, os recursos digitais são considerados tanto como ferramentas aplicadas quanto como produtos, ou seja, recursos gerados pelo projeto. Por um lado, os acervos digitais que formam parte de nossas fontes de documentos, a linguagem XML e o trabalho com o eDictor funcionam como ferramentas. Por outro, esses meios que tanto têm dinamizado nosso trabalho nos dão a possibilidade de criar novos recursos, como o georreferenciamento de documentos e nosso catálogo digital, que num outro momento poderão servir como ferramentas para outros grupos e temas de pesquisa.

O desenvolvimento e a utilização dessas tecnologias digitais possibilita a democratização do acesso a esses escritos, permitindo a construção de um ambiente colaborativo e que favorece avanços dirigidos à flexibilidade e ampliação de uso, gerando contribuições para o trabalho filológico e para pesquisas linguísticas. Assim, defendemos que o entrelaçamento entre as humanidades e o digital pode gerar contribuições mútuas bastante frutíferas e ressaltamos isso em nossa apresentação no VIII Seminário Hispano-Brasileiro de Pesquisa em Informação, Documentação e Sociedade 2019.

Os elogios que recebemos das coordenadoras e coordenadores da mesa de Humanidades Digitais no evento nos deram mais ânimo, mais orgulho pela dedicação das pesquisadoras que têm construindo e colaborando com o MAP, parte delas voluntárias e/ou estudantes de graduação - como nós quatro. Por fim, convidamos a todas leitoras e todos os leitores a conhecer o MAP e a inserir o digital em seus projetos.

\section{Referências}

ARQUIVO NACIONAL TORRE DO TOMBO. Denúncias Contra Francisca Luís, 2011. Disponível em: https://digitarq.arquivos.pt/details?id=4510000 Acessado em: 30 de dezembro, 2019. 
FERREIRA, P. T. Filologia como curadoria: o caso Pessoa. Filologia e Linguística Portuguesa, v. 18, n. 2, p. 231-262, 2016. Disponível em: http://www.revistas.usp.br/flp/article/view/110219 Acessado em: 14 de dezembro, 2019.

MONTE, V. M. do; PAIXÃO DE SOUSA, M. C. Agora andam me jurando a pele: Escritos de mulheres e escritos sobre mulheres na América Portuguesa. Projeto de pesquisa, Programa Unificado de Bolsas (PUB), Universidade de São Paulo. São Paulo, 2017. Disponível em: http://www.nehilp.org/ nehilp/HD/MAP/MAP Projeto 2017.html Acessado em: 18 de outubro, 2019.

MONTE, V. M. do. M.A.P. (Mulheres na América Portuguesa): Mapeamento digital de escritos de mulheres e sobre mulheres no espaço atlântico português - Vertente filológica. Projeto de pesquisa, Programa Unificado de Bolsas (PUB), Universidade de São Paulo. São Paulo, 2018. Disponível em: http://www.nehilp.org/ nehilp/HD/MAP/MAP Projeto 2017.htmlAcessado em:18 de outubro, 2019.

MONTE, V. M. do; PAIXÃO DE SOUSA, M. C. Por uma filologia virtual: O caso das atas da câmara de São Paulo (1562-1596). Revista da Abralin, v. 16, p. 239-264, 2017 Disponível em: http://revistas.ufpr.br/abralin/article/view/51938 Acessado em: 18 de outubro, 2019.

PAIXÃO DE SOUSA, M. C.. M.A.P. (Mulheres na América Portuguesa): Mapeamento digital de escritos de mulheres e sobre mulheres no espaço atlântico português. Projeto de pesquisa, Programa Unificado de Bolsas (PUB), Universidade de São Paulo. São Paulo, 2018.

PAIXÃO DE SOUSA, M. C.; MONTE, V. M. do. M.A.P. (Mulheres na América Portuguesa): Mapeamento de escritos de mulheres e sobre mulheres no espaço atlântico português a partir de métodos das Humanidades Digitais. Projeto de pesquisa, Conselho Nacional de Desenvolvimento Científico e Tecnológico - Edital Universal: São Paulo, 2018.

PAIXÃO DE SOUSA, M.C.; KEPLER, F.N.; FARIA, P.P.F. E-Dictor: Novas perspectivas na codificação e edição de corpora de textos históricos. In: SHEPHERD, Tania; SARDINHA, Tony Berber; PINTO, Marcia Veirano (Org.). Caminhos da linguística de corpus. Campinas: Mercado de Letras, 2010.

PAIXÃO DE SOUSA, M.C.; KEPLER, F.N; FARIA, P.P.F. E-Dictor (Version 1.0 Beta 10). 2013. Disponível em: https://edictor.net/download Acessado em: 28 de dezembro de 2019.

UNIVERSIDADE DE SÃO PAULO. Grupo de Pesquisa Humanidades Digitais. Catálogo M.A.P.2019. (Version Beta), Disponível em:http://map.prp.usp.br/MAP Equipe.html Acessado em: 30 de dezembro, 2019. 